\title{
RESEARCH TRENDS FOR DECISION AIDS FOR CHANGE MANAGEMENT
}

\author{
X. Boucher ${ }^{1}$, D. Crestani ${ }^{2,}$ M. A. Girard ${ }^{1}$ \\ ENSM.SE, 158 Cours Fauriel, 42023 Saint Etienne Cedex \\ LIRMM, 161 Rue Ada, 34392 Montpellier Cedex 5
}

\begin{abstract}
This paper presents the analysis of two surveys, one academic and one industrial. The goal was to provide research perspectives in the field of change management for industrial systems. This communication is the result of multi-disciplinary study (ADESI project) launched by the National Centre of Scientific Research, CNRS. The "raison d'être" of this work, is to answer the strong need to coordinate both academic and industrial communities as well as the necessity of multi-disciplinary approaches for decision-aids applied to change management. Copyright (C) 2006 IFAC
\end{abstract}

Keyworks: Evolution of industrial systems, change management, management of organisations, decision aids.

\section{INTRODUCTION}

The permanent advances in the technological environment, the rapid evolution of the consumers, or the changes in social constraints increase exponentially the difficulties in making strategic decisions. The pace of change as well as the complexity of factors to consider augment constantly. Organisational and social aspects of the enterprise now have to be taken into account on the same level as technological aspects. Still, managers lack methods and tools to assist such decision processes. These have to be deeply integrated in those dimensions : technological and economical, as well as organisational and sociological.

The French CNRS Research Action ADESI ${ }^{1}$ focused on "decision aid to manage the evolution of industrial systems” (Adesi, 2004). The goal was to identify research orientations for the future. ADESI was based on the participation on multi-disciplinary laboratories ${ }^{2}$ with scientists from the economical, sociological and industrial engineering fields.

\footnotetext{
${ }^{1}$ Specific Action $\mathrm{N}^{\circ} 64$ with CNRS fundings - RTP N 47 : Production Coopérative Médiatisée ${ }^{2}$ LIRMM - LGI2P Mines d'Alès - LICIA INSA Strasbourg - LARESP IFMA - G2I/OMSI Mines Saint-Etienne
}

Industrial and research actors participated in the project. This was done to assess industrial needs, existing solutions, and research perspectives for these decision aids.

Section 2 gives a brief synthesis of the industrial needs analysis and of the positioning of the French research. Section 3 suggests a set of research orientations : these outlines are pertinent for French research, but they are even more interesting at the European level.

\section{NEEDS IDENTIFICATION}

Two surveys one industrial and the other academic were synthesized. The former focuses on industrial requirements, and the latter deals with the strengths and weaknesses of French research in decision-aids applied to changes in industrial systems. Both surveys put forth general trends for future work on change management.

\subsection{Industrial Survey}

The survey involved around sixty public or private French enterprises. Since the objective was to define general trends, there was no selection of the 
enterprises depending on criteria like their activities, size or turnover. Therefore we worked with a very diverse group of companies. The survey was based on semi-structured managerial interviews. An interview guide and questionnaire was created in a first step of collaboration with a limited number of firms. This guide was later used for direct interviews, supervised by scientists having a multi-disciplinary culture in industrial management. This industrial survey dealt with two decision levels in these firms : the top and operational management.

The analysis of the results clearly shows the importance of the change management for managers. More than $80 \%$ of the firms emphasize that their ability to have a adequate management of changing situations has a strong impact on their overall performances. The need of some way to anticipate future changes is confirmed in more than $80 \%$ of the questionnaires. Furthermore, these managers confirm that heavy strategic changes, having economical, organisational as well as socio-human impact, are more frequent today (61\%) or even extremely frequent (19\%) than in the past. Concerning the type of changes they are confronted with, firms emphasize that the development of industrial alliances, access to the international market, as well as deployment of new forms of legal structure are becoming more common. On the contrary, our study shows that internal changes like technological advances, changes in work methods, or internal structures are becoming less frequent. This tendency underlines the importance of the alteration of organisational frontiers, and the impact of new modes of operation like the extended enterprise.

The analysis of factors that inhibit the adoption of needed changes shows that the more frequent obstacles (75\% of the answers) concern organisational and cultural aspects (Culture and motivation, making sense of the changes and personal investment of the actors) much more than the technical. These trends are also confirmed by a study published by the American Management Association (Ama, 1995) involving 250 firms. The conclusion of this survey emphasized that the main causes of failure in change projects are based on organisational and socio-human factors, notably due to a deep lack of understanding and of control of such aspects from the managers.

The more common change management currently used methods receive satisfactory evaluations among industrial management. Three main types of approaches can be identified : (i) methods and tools oriented on socio-human factors (communication, HRM and vocational training, negotiation, mediation) ; (ii) project management tools (project team building, project planning, share of experiences) ; (iii) performance control tools (dashboard, economical forecasting). Communication appears as a common way to try and manage changes. The impact of the personal investment of the actors is really emphasized, since more than $50 \%$ of the firms use the deployment of project teams and the sharing of experiences, with the objective to improve business changes. Other types of tools, oriented on value management or on change anticipation are less frequently used. Thus, our survey companies are clearly oriented on tools managing the deployment of change (tactical decision). But they are little interested in decision supports which aid in choosing the right alterations to be implemented. This would create a longer term strategic view.

Finally, the analysis of the future industrial decision supports needs shows three main directions : (i) the necessity to integrate a multi-dimensional view of the performances; (ii) the need to better evaluate the impacts of the changes on company skills; (iii) the necessity to improve methods to control change deployment on the organisational and human factors.

This industrial survey highlights the need for multidisciplinary work on change management. It underlines the importance of socio-cognitive and organisational factors, as well as the requirements for innovative approaches for performance management. However the survey was broad and led to general trends. A more profound study would delineate the industrial needs, considering a firm typology, the activity field or even the type of actors implicated in change management (top management, intermediary management, employees,...). The needs are not the same in each of these contexts.

\subsection{Academic survey}

The 3 main goals of the academic survey were to identify (i) French laboratories working on the issue "decision aid to manage the evolution of industrial systems", (ii) current and prospective research orientations and to evaluate (iii) the links with the industry. The questionnaire used for the survey was oriented on the scientific positioning and production of the laboratories (or research teams) concerned, on the evaluation of the pluri-disciplinary, international and industrial aspects of the current research in that field, and finally on the research perspectives expressed.

Overall, 1200 scientists work on this issue in France (including CNRS and other laboratories). $60 \%$ of the laboratories identified belong to the engineering sciences domain (STIC Division of the CNRS), when the $40 \%$ belong to economical and socio-human sciences (SHS Division of the CNRS). $40 \%$ of these French laboratories have participated in the survey. Within the CNRS Division STIC, the $61^{\text {st }}$ section (on 
automatics and industrial engineering) is the more represented (64\% of the STIC scientists working on this issue belong to section 61), certainly because of direct links with several research orientations: research on production systems, mathematical approaches of decision-aid, or temporal evolution of complex systems. Then come section 27 (computer science) and section 60 (mechanical engineering) each with $16 \%$ of all the STIC scientists working on that area. Within the SHS Division of the CNRS the distribution among the distinct sections is more balanced. The section 6 (management sciences) comes first with $33 \%$ of all the SHS scientists working on this issue. Then come the section 5 (economical sciences - $17 \%$ ), the section 19 (sociological sciences - 17\%), the section 70 (education sciences - 17\%). The two last sections are poorly represented (section 7 "linguistic sciences" and the section 2 "legal issues for public organisations”).

Table 1 and Table 2 below, present the most common keywords when one wants to identify the scientific key-word positions of the SHS and STIC teams involved. The tables show the current positions as well as the prospective positions within three years. We can observe a broad stability of the SHS teams, concerning the research issues identified. These teams mainly work in two large directions: organisational structures of the enterprises and knowledge and skill management.

Concerning the STIC teams, there is a clear difference between the current and the prospective positioning : they go from production-systemscentred issues, towards research more opened on a global understanding of enterprises' organisations and dynamics. Such an evolution probably shows a convergence between research orientations of both the STIC and the SHS CNRS Divisions. This factor should make easier the multi-disciplinary collaboration between those scientific fields.

A majority of the teams involved in the study (53\%) confirms strong links with distinct scientific disciplines. However, we can underline that the STIC community appears more opened both on interdisciplinary and international collaborations. Indeed, the number of STIC teams having multi-disciplinary collaborations is twice the number of SHS teams. STIC teams mainly cooperate with Sociological, Management or Economical Sciences. Most of the international collaborations take place in European projects, and the mainly implicate STIC teams.

Table 1. Scientific positioning of SHS teams

\begin{tabular}{|c|c|c|c|}
\hline \multicolumn{2}{|c|}{ Current scientific positioning } & Score & Prospective scientific positioning (3 years) \\
\hline Keywords & 22 & Keywords \\
\hline $\begin{array}{c}\text { Evolution of competencies } \\
\text { (individual, collective, organisational) }\end{array}$ & 18 & Organisational flexibility et reactivity \\
\hline Evolution and trajectories of organisations & 17 & $\begin{array}{c}\text { Evolution of competencies (individual, collective, } \\
\text { organisational) }\end{array}$ & 18 \\
\hline Organisational flexibility et reactivity & 17 & Knowledge Management, Enterprise memory, etc. & 18 \\
\hline Knowledge Management, Enterprise memory, etc. & 16 & Organisational dynamics \\
\hline Organisational dynamics & & 14 \\
\hline
\end{tabular}

Table 2. Scientific positioning of STIC teams

\begin{tabular}{|c|c|c|c|}
\hline \multicolumn{2}{|l|}{ Current scientific positioning } & \multicolumn{2}{|l|}{ Prospective scientific positioning (3 years) } \\
\hline Keywords & Score & Keywords & Score \\
\hline $\begin{array}{c}\text { New organisational forms } \\
\text { (Networked , virtual, distributed organisations) }\end{array}$ & 18 & $\begin{array}{c}\text { New organisational forms } \\
\text { (Networked , virtual, distributed organisations) }\end{array}$ & 16 \\
\hline Evolution of information systems & 16 & Decision-making aid applied to change management & 15 \\
\hline Process-based management and control & 15 & $\begin{array}{l}\text { Integration of organisational factors in performance } \\
\text { evaluation }\end{array}$ & 13 \\
\hline $\begin{array}{l}\text { Integration of organisational factors in performance } \\
\text { evaluation }\end{array}$ & 14 & Process-based management and control & 12 \\
\hline Evolution of coordination and cooperation modes & 14 & Organisational flexibility and reactivity & 12 \\
\hline
\end{tabular}

Industrial relationships are quite extensive (75\% of research teams do confirm such collaborations), most of the time with large companies more than with PMEs. Resarch orientations are most of the time inspired by industrial concerns (90\%). Most of the teams believe that the industrial demands for innovations and technology transfers concerning change management will increase in the coming years (78 \%).

In conclusion, the academic survey built with the STIC and SHS Divisions emphasizes the importance of the scientific community working on change management. This community is numerous and multi-disciplinary, with a potential convergence of 
research orientations. This convergence requires improving progressively the coordination between qualitative and quantitative research. The survey puts forth the beneficial link between research and industry on this issue, and the national and European initiatives to improve both international and multidisciplinary collaborations.

\section{ROAD-MAP FOR FUTURE RESEARCH}

The identified industrial needs are the basis to define a road map of future research for enterprises' evolution management. This plan should structure and guide the research by associating the multidisciplinary scientists. In the following sections, we propose several short-term structured research actions, which appear as essential to create and to facilitate the development of a cross-disciplinary community for the enterprise change management. Strategic application domains are suggested.

\subsection{Study of the enterprises' evolution mechanisms}

As highlighted by the industrial survey, enterprise's evolution management requires a comprehensive approach integrating all the scientific domains and considering all the decision levels of the enterprise.

A cross-disciplinary framework is fundamental to model and understand the evolution of an organisation (Doz, 1994) and organisational learning can provide the basis for such a framework. It is based on a collective and accepted description that facilitates the understanding of the enterprise's transformation mechanisms, their impacts and applications to real world problems.

Organisational learning can be taken into account during the transition from an enterprise structure to another. But additional work must be done to control the long-term transformation of firms. Thus, the concept of organisational trajectory which tries to model the long-term evolution of an enterprise's structure is relevant too. It has been yet used in management (Nelson et Winter, 1982), in engineering (Geram, 1999), or for distributed enterprise structures (Zaidat, 2005). However, profond theoretical work remains essential to ensure the convergence of these distinct sources.

The control of the organisational evolution needs also to develop some performances estimation methods for organisational evaluation. Performance evaluation must involve several dimensions. Historical tools were only economically oriented. Today, they are replaced and by scorecards integrating human, informational and organisational capitals of the enterprise (Kaplan, 2004). However, most of the researchers claim that one of the most important limitations of this tool is that, because of the quantity of available information, there doesn't seem to be a selection guide to choose the relevant performances indicators. So it is essential to research solutions leading to new tools which integrate immaterial capital, organisational structure, and model the dynamic and holistic viewpoints of the enterprise.

This kind of performance-guided control imposes a reference frame positioning the organisational trajectory of the enterprise. Currently the research work (Woodward 92), (Boynton 91) mainly cover technical viewpoints. The social dimension of the enterprise must be integrated to build new reference frames. These systems must also be more explicitly open to knowledge management and organisational learning. The definition of more complete (integrating social and technical points of view) and relevant (with more pertinent performance indicators) systems of reference should better control enterprises transformations and provide new operational decisional aided tools.

\subsection{Decisional processes studies for enterprises' transformation control}

Today, most of current decisional aided approaches for the control of enterprises' transformations use the concept of an evolution scenario. These scenarii allow a comparative analysis of change alternatives, from a given starting point to a set of potential target configurations. For example in social science, scenarios are modelled by using the concept of transition (Mintzberg, 2001), by the different classes of possible "evolution crisis" (Grenier, 1972) or the transition factors for network enterprises (Grecopme, 2002). More recently in engineering, the concept of change scenario has been used to build decision aids to manage change in information systems (Carvalho, 2002). However, this concept of scenario remains poorly formulated and still requires an extensive theoretical work.

All these concerns illustrate the importance of a cross-disciplinary approach. However, this "scientific globalisation" needs a deeper analysis of the frontiers between soft and hard sciences, as well as the limits of a rigorous formalisation of change mechanisms. Indeed, how to define what decision processes should be computed?

\subsection{Need of more holistic and consistent enterprise reference architectures}

Company’s reference architecture (Lillehagen, 2005) is a simplified and aggregated description of the basic structure of components and organisation of the 
enterprise. This framework better deals with enterprise complexity and decision processes for system engineering and change management. However, there are still many drawbacks that a more holistic and cross-disciplinary approach could reduce:

- Some architectures use overlapping approaches where the underlying concepts are not explicitly defined. This creates obstacles for a correct accepted and understanding in industry (Lillehagen, 2005). A cross-disciplinary approach should define a generally agreed terminology which is semantically enriched by the knowledge of the different scientific domains concerned.

- Multiple examples of failed change programs prove the importance of mutual consistency between reference architectures applied to specific domains (Hoogevorst, 2004) (Kotter, 1995). Research clearly linked organisational inertia to segmentation and incoherence, whereas the ability to change relates to coherence and integration (Pettigrew, 1998). Such integration requires a rigorous and shared formalisation of the modelling concepts covering all points of view on a firm.

- Architecture concepts are strongly connected to engineering. But current enterprise architectures like TOGAF (Open Group 2000) focus on informational and business facets of the enterprise and therefore neglect the knowledge dimension. To extend this reduced viewpoint, integration needs to build a knowledge architecture too (Lillehagen, 2005).

- Reference architectures can define methodological frameworks available to assist the user by structuring their thinking during their architectural work. Often this oriented and guided work lacks like GERAM (Geram, 1999) of operational models to describe enterprise complexity and evolution. Due to the lack of explicit models, a generic architecture, intellectually interesting, is not able to assist the user all along the aided decision process.

\subsection{A better integration of modelling languages}

In the last 2 decades, enterprise modelling (Petit, 2002) has developed a less restricted vision of enterprise in order to ensure real enterprise engineering. However, the development of enterprise modelling still suffers from crucial limitations :

- Numerous partially overlapping enterprisemodelling languages are available (Petit, 2002). It is essential to employ the best part of each of them (description, analysis, domain of expertise, etc.) to develop a unified language allowing to consider all the viewpoints (social, technical, etc.) required in the long-term. To ensure the interoperability of existing models, research attempts to develop a centralized generic model which supports the exchange of information and knowledge (Vallespir, 2003). The European project UEML (UEML, 2001) has proved the feasibility of this approach. However, this work remains partial and limited to 3 languages (IEM, EEML, GRAI). Moreover, the coherence and the mapping of the concepts is difficult to achieve and the problem of the operational semantic of the languages is not really tackled.

- The management of the change mechanisms must necessary use a profound study of the decisional process. At present, few computer languages are able to deal with this type of process. So, to control the transformation of the firms, it is crucial to develop new modelling and analytical tools specialised in decision processes (especially strategic).

- In most of the enterprise models the human and social points of view remain neglected. This limitation cannot be accepted because it is now wellknown the human entity is one of the key-factors of the enterprise performance (Grabot et al., 2000). The concept of multi-facets skill is used to characterise individually the workers (Hind, 2000). The social or collective facets of the human behaviour, the connection to process and enterprise performance remains poorly formalised (Bennour, 2004). Consequently, this research domain must be open to soft sciences.

\subsection{A better technology transfer}

The increasing the rate of change in enterprises, and the research programs are catalysed by new emerging organisational structures (Camarinha, 2003). Thus, industrial transfer on decision-aided methods for enterprise change control must particularly address extended and network enterprises structures.

Moreover ADESI project conclusions accentuate other modes/directions for industrial transfer:

- An European study (NewWorkorg, 1999) emphasizes that most of the present works on the change management are concentrated on large scale manufacturing enterprises problems. Evidently, Small and Medium Enterprises (SME) are a key factor of economical growth. It is essential to develop industrial projects centred on the management of change in SME like (Futura, 2000).

- Many research works demonstrate that product and organisational innovation plays a key role for the growing and the dynamism of a Medium Scale Enterprise (Chabal, 1997). Studies should be based on innovation in order to know and control its influence on enterprises evolution (TMR, 2000).

- It is indisputable that the western society is more and more services oriented. Today, this particular research topic is neglected (NewWorkorg, 1999) and must constitutes a new and important studies domain.

- For the new class of enterprise, the formalisation of the existed links between the general performance and the different organisational and coordination modes is necessary to manage and control the change process. 
The transfer from science to industry demands an action research (Argyris et al., 1978) where an industrial organisation leaves the old paradigm to embrace the more recent theories which seem to be better adapted to reality. However, short-term logic from industry cannot be applied to all the actors of the society and more particularly to the research domain.

\section{CONCLUSION}

This paper articulates the necessity of strong research on enterprise change management as they concern industrial requirements. Based on real-life industrial problems, this work demands the development of multi-disciplinary studies combining STIC and SHS academic actors. Understanding decisional processes seems essential to integrate the tactic and strategic levels of decision. Finally, concrete operational tools and methodologies become unavoidable to promote research to industry transfer.

\section{REFERENCES}

Adesi, (2004). Action Spécifique ADESI - Aide à la Décision pour l'Evolution Socio-Technique des Systèmes Industriels. Final report, September.

Ama, (1995). Survey from American Manager Association, http://www.amanet.org/

Argyrys, C. and Schön, D. A., (1978). Organizational learning : a theory of action perspective, (Addison-Wesley Publ. Comp. (Ed.)).

Bennour, M., (2005), Contribution à la modélisation et à l'affectation des ressources humaines dans les processus, PhD Thesis, University of Montpellier 2.

Bidanda, B., Ariyawongrat, P., LaScola Needy, K., Norman, B. A. and Tharmmaphornphilas, W., (2005). Human related issues in manufacturing cell design, implementation, and operation: a review and survey, Comp. \& Indus. Eng., 48, 507-523.

Boynton A., Victor B., (1991). Beyond Flexibility: Building and managing dynamically stable organisations, California Man. Rev., 34/1, 53-66.

Camarinha-Matos L.M., (2003). New collaborative organizations and their research needs, Fourth Working Conference on Virtual Enterprises, October 29-31, Lugano, Switzerland.

Carvalho, A., (2002). Evolution du Système d'Information fondée sur l'Urbanisation. PhD thesis, Université Paris VI, 2002.

Chabbal, R., (1997). Un plan d'action pour les PME innovantes, work report for French gouvernement.

Doz Y., Ingham M., Koenig G., (1994). Apprentissage organisationnel : pratiques et théories. Revue Française de Gestion, 97.

Futura, (2000), Conception et développement d'un instrument d'aide à la décision pour les PME, Futura national project 4406.3, Fribourg university.
Geram, (1997). GERAM: Generalized Enterprise Reference Architecture and Methodology ISOTC184/SC5/WG1, N398.

Grabot, B. and Letouzy, A., (2000). Short-term manpower management in manufacturing systems : new requirement and DSS prototyping, Computers in Industry, 43, 11-29.

Grecopme, (2002). GRoupements d'Entreprises COopérantes, Potentialités, Moyens, Evolutions, project report.

Grenier, L., (1972). Evolution and Revolution as Organisations Growth, Harward Business Review, 4, 37-46.

Hinds, P.J., Carley, K.M., Krackhardt, D. and Wholey D., (2000), Choosing work group members : Balancing similarity, competence and familiarity, Organisational Behaviour and Human Decision Processes, 81 (2), 226-251.

Hoogervorst, J., (2004). "Enterprise architecture : Enabling integration, agility and change" Int. Journal of Cooperative Information Systems, 13(3), 213-233.

Lillehagen, F. and Karlsen, D., (2005). Enterprise architectures - survey of practices and initiatives INTEROP, ESA'05, 1st International conference on interoperability of enterprise software and applications, Geneva.

Kaplan, R.S. and Norton, D. P., (2004). Measuring the strategic readiness of intangible assets. Harvard Business Review, pp.52-63.

Mintzberg, H., (2001). Structure et Dynamique des organisations, Editions d'Organisations, Paris.

Nelson, R., Winter, S., (1982). An evolutionary theory of economic change, (Belknap Press (Ed.)).

NewWorkorg, (1999). New Forms of Work Organisation and Productivity, report for the european commission, http://europa.eu.int/comm/ employment_social/news/2003/jan/workorg_en.pdf

Open Group, (2000). TOGAF: The Open Group Architecture Framework, Doc N 1910, version 6.

Petit, M. and Doumeingts, G., (2002). Enterprise Modelling State of the Art, D1.1. of U.E.M.L. Project. Available from http://www.UEML.org.

Pettigrew, A., (1998). Success and Failure in Coorporate Transformation Initiatives, in: Galliers, R.D., Baets, W.R., Inf. Tech. and Organizational Transformation, Chichester (Wiley (Ed.)).

TMR (2000). Innovation In Services: A Systemic Approach to Technological and Organizational Change, European project FMBI983331.

U.E.M.L., (2002). European projects reports available from http://www.UEML.org.

Vallespir, B., Braesch, C., Chapurlat, V. and Crestani, D, (2003), L'intégration en modélisation d'entreprise : Les chemins d'UEML, MOSIM'03; 140-145.

Zaidat, A., Vincent, L. and Boucher, X, (2005). A framework for organization network engineering and integration, Robotics and Computer Integrated Manufacturing, 21 (2005), pp 259-271. 